Revista da Rede Brasileira de História da Geografia e Geografia Histórica

$11 \mid 2019$

Mapas e mapeamentos: conhecer, apresentar e agir

\title{
A imaginação geográfica nos manifestos modernistas de Oswald de Andrade
}

La imaginación geográfica en los manifestos modernistas de Oswald de Andrade The geographical imagination in Oswald de Andrade's modern manifests L'imaginaire géographique dans les manifestes modernistes d'Oswald de Andrade

\section{Felipe Cavalcanti}

\section{(2) OpenEdition}

\section{Journals}

Edição electrónica

URL: https://journals.openedition.org/terrabrasilis/4056

DOI: $10.4000 /$ terrabrasilis.4056

ISSN: 2316-7793

Editora

Rede Brasileira de História da Geografia e Geografia Histórica

\section{Refêrencia eletrónica}

Felipe Cavalcanti, «A imaginação geográfica nos manifestos modernistas de Oswald de Andrade», Terra Brasilis [Online], 11 | 2019, posto online no dia 31 agosto 2019, consultado o 05 dezembro 2022 URL: http://journals.openedition.org/terrabrasilis/4056 ; DOI: https://doi.org/10.4000/terrabrasilis 4056

Este documento foi criado de forma automática no dia 5 dezembro 2022.

All rights reserved 


\section{A imaginação geográfica nos manifestos modernistas de Oswald de Andrade}

La imaginación geográfica en los manifestos modernistas de Oswald de Andrade The geographical imagination in Oswald de Andrade's modern manifests L'imaginaire géographique dans les manifestes modernistes d'Oswald de Andrade

Felipe Cavalcanti

\section{Uma palavra introdutória: a centralidade da imaginação na geografia}

A geografia é, segundo a etimologia, a "descrição" da Terra; mais rigorosamente, o termo grego sugere que a Terra é um texto a decifrar, que o desenho da costa, os recortes da montanha, as sinuosidades dos rios, formam os signos desse texto. [...] "Em toda parte", escreveu Vidal de La Blache a respeito da floresta [...] [ela] continua presente. Ela povoa a imaginação e a visão. É a

vestimenta original da região [...] Presença, presença incessante, quase inoportuna, sob o jogo alternado das sombras e da luz, a linguagem do geógrafo sem esforço transforma-se na do poeta. Linguagem direta, transparente, que "fala" sem dificuldade à imaginação, bem melhor, sem dúvida, que o discurso "objetivo" do erudito, 
porque ela transcreve fielmente o "texto" traçado sobre o solo. (Dardel, 2011: 2-3)

1 A epígrafe acima sugere a possibilidade de conciliar-se imaginação, arte e ciência. Não obstante, a tradição geográfica à qual o autor direciona a sua crítica situa o fazer geográfico na imagem do erudito e sua objetividade. Defendemos, porém, que a Geografia não se faz sem imaginação geográfica. Assim, esta se encontra, notadamente, quando negada enquanto tal. Uma de suas formas é aquela erigida em discursos criadores de "ideologias geográficas" (Moraes, 2008), muitas vezes se tornando hegemônicas e forjando visões estereotipadas sobre o povo e seu território. Para que elas funcionem, é imprescindível que sua qualidade ideológica e imaginativa seja negada, dotando-as de ares de neutralidade. Através destas ideologias, seus sujeitos são ocultados e pretendem autolegitimar seus discursos e valores. Ao assim fazê-lo, porém, revelam-se como construção geopolítica e geohistórica, a qual marginaliza e impossibilita outros corpos, saberes e espaços (Maldonado-Torres, 2009: 338-339; Cruz, 2017: 24). Este modus operandi ocorre, por sua vez, ao se proclamar a suposta natureza universal do conhecimento e revesti-lo sob o manto da neutralidade, promovendo assim uma hierárquica e homogeneizadora ordem dos lugares. Esta ordem entroniza uma organização do espaço que se pretende única, e, por isso, global.

Colocar esse debate acerca da imaginação no centro do problema de análise apresentase como um caminho frutífero para desnaturalizar formulações moderno-coloniais, à medida que possibilita forjar outras utopias e outros significados. É possível analisar a obra de Oswald de Andrade a partir desta chave interpretativa, onde lugares e sujeitos em posições marginais são ressignificados e postos ao centro, valorizando saberes e geografias até então negadas: a defesa da toponímia Pindorama, em lugar de Brasil; o bárbaro tecnizado, em lugar do índio romântico.

Ainda sobre a importância e o lugar dessa imaginação, Gregory (1994) identifica concepções as quais vão em direção à exata medida da orientação aqui assumida:

Em um nível, essas geografias imaginativas são "conhecimentos locais" singulares com seus distintivos silêncios, espaços em branco e distorções. [Em outro nível] nossas geografias imaginativas (dentro e fora da academia) são tanto globais quanto locais. Elas articulam não simplesmente diferenças entre este lugar e aquele outro, inscrevendo diferentes imagens daqui e de lá, mas também formatam os caminhos nos quais, das nossas perspectivas particulares, concebemos as conexões e disjunções entre eles. O "global" não é o "universal, em outras palavras, mas é ele próprio uma construção situada. (Gregory, 1994: 203-204. Tradução livre) ${ }^{1}$

4 Essa perspectiva também vai de encontro às proposições de Antônio Carlos Robert Moraes, na medida em que ambos destacam a presença de conteúdos geograficamente pertinentes (assim, dotados de geograficidade) fora da Geografia com "G maiúsculo", a acadêmica e disciplinar:

as mais eficazes ideologias geográficas não se apresentaram sob a rotulação explícita de "geografia", e circunscrever as análises aos textos gerados no âmbito disciplinar redundaria em perder os mais importantes discursos norteadores da produção do espaço brasileiro e da própria produção das representações hegemônicas deste espaço. (Moraes, 2008: 14. Grifos nossos)

Deste modo, tais considerações introdutórias são importantes na medida em que, mutatis mutandis, Oswald de Andrade irá implodir, com sua literatura, essas versões das narrativas e imaginações sobre o espaço, uma vez que ele sinaliza o aspecto parcial e subjetivo do que entendemos aqui por "ideologias geográficas". Assim sendo, ele irá, ao 
mesmo tempo, propor uma nova leitura do Brasil: utópica e imaginativa, com fortes contornos geográficos.

\section{A imaginação geográfica nos manifestos oswaldianos: a floresta, a escola, o rurbano ${ }^{2}$}

6 Um possível modo de analisar a imaginação geográfica na literatura oswaldiana se dá a partir de um temário comum ao Pensamento Social Brasileiro: os dualismos, cabendo dois Brasis antípodas, conflitantes, em um mesmo território. Em Oswald, esse binarismo é colocado na oposição floresta x escola. Ela emerge a partir de cotejamentos entre os manifestos modernistas do literato, nos anos 1920 , atendo nossa análise, ${ }^{3}$ portanto, aos manifestos de 1924 (poesia pau-brasil) e 1928 (antropófago). Tais unidades binárias aparecem ora de modo explícito, ora analítico e/ou sugestivo, compondo assim a referência principal que deságua no conceito de rurbanização para a interpretação e retratação da "realidade brasileira". O recorte proposto pode ser justificado não somente pela recorrente avaliação dos referidos escritos de Oswald como sendo os mais característicos, prolíficos e influentes para a cena e a intelectualidade modernista, mas também pela riqueza da sua imaginação geográfica, a qual demonstraremos ao longo do artigo.

7 A postura enérgica e confrontadora de nosso literato em relação à literatura tradicional, combinando suas ideias de modo genial e contraditório - ou mesmo "esdrúxulo", de acordo com Lucia Helena (1985) - faz Oswald, à beira da morte, reencontrar-se com a criança que já tinha sido um dia, no sentido de retomar ideias da juventude de modo radicalmente afirmativo. Seu espírito infante ${ }^{4}$ nunca deixou de ser um complexo híbrido de birra, criatividade e afirmação. Nesse sentido, nos momentos finais de sua vida, imbuído de vontade de afirmação de sua obra, reabilitando suas formulações da antropofagia (negadas durante o período de sua filiação marxista) e, por outro lado, temendo as recriminações ${ }^{5}$ da plêiade das mais variadas nuances do modernismo (em particular, suas vertentes conservadoras, como o Grupo Verde Amarelo), Oswald está sob as ordens de mamãe (subtítulo de seu diário confessional, cujo prenome fora alcunhado de "um homem sem profissão"), escrevendo suas memórias. Nelas, Oswald dá destaque às suas primeiras experiências na escola. Esta, possível lugar traumático de medo e de recalque, é por ele transfigurado em lugar de luta, crítica e afirmação, no qual a geografia representa o elemento perturbador. Ele dá um golpe bem-humorado, e vislumbra uma espécie de "geografia nova", ${ }^{6}$ talvez sem que o saiba, abrindo caminho para suas utopias, para o "novo homem" e o "novo mundo". Assim o faz:

No quarto ano, produziu-se a crise esperada. Encontrei pela frente um professor teutônico, pré-nazista, de peito emproado, purista e autoritário. [...] Chamava-se Carlos Augusto Germano Knuppell e era um produto da Faculdade de Direito, de que fazia os mais elevados elogios. Para ele, ser bacharel pela escola do Largo de São Francisco traduzia um incalculável penhor de saber e de caráter. [...] meu duelo desigual com o "Doutor Kinipel" atingiu o auge. [...] 0 primeiro exame em que eu o defrontei foi o de Corografia do Brasil, de que ele era catedrático. Durante o ano todo nos ensinou a decorar nomes de cidades, lagos, montanhas e rios, pouco interesse mostrando por qualquer ideia de cartografia. Os mapas fugiam de suas aulas secas. Na hora em que eu ia ser oferecido em sacrifício à ferocidade do professor, a sala de exame se encheu de colegas. Todo mundo queria assistir ao sádico espetáculo. Tirei o ponto "Portos de Segunda Ordem". [...] quando Kinipel 
gritou: - Não senhor, não quero nada de cor! O senhor vai realizar uma viagem estranha! Vai subir num navio num porto do Estado do Rio Grande do Sul e desembarcar na Bahia. Exijo apenas uma condição para aprova-lo: que não entre nesse percurso em nenhum porto de primeira ordem. Vamos! [...] não achando meio, na minha pobre e mal exercitada memória cartográfica, onde pôr o pé, exclamei: - Rio de Janeiro! Foi uma gargalhada geral. Era o que ele esperava. Gritou: - Rio de Janeiro! A Capital da República, porto de segunda ordem! Vou expulsá-lo da banca! Mais morto do que vivo, eu respondi: - Desci para ir de barca a Niterói! o estrépito da classe atingiu o delírio. (Andrade, 2002: 77-79)

8 Assim, a escola revela-se um espaço aberto de possibilidades e de tensões, onde "De qualquer lado que girasse minha curiosidade de criança, alimentavam-na do mais rico material da imaginação e da realidade brasileira." (Andrade, 2002: 49). A geografia bem (não) poderia ser um caminho a ser evitado por Oswald, todavia, como fez melhor em vida, dela se apropriou pela devoração. Coube a Oswald a totemização desse tabu, ${ }^{7}$ estando essa geografia e o espaço largamente presentes, na qualidade de metáforas ou de imaginação geográfica mais aprofundada. Oswald revela, metaforicamente, a imolação, seu "rito sacrificial" frente a uma geografia enfadonha, quantitativa e enumerativa; a blague; a criatividade. A síntese de sua postura como intelectual, artista e (por que não?) "geógrafo", a bordo de suas primeiras viagens e rumos pela geografia, através da qual busca correções e novas escalas. Essa proposta de uma nova geografia coloca uma busca de referências para orientar as bússolas nacionais. Isso acontece via Manifesto da poesia pau brasil, onde há a defesa da exportação de uma arte própria, findando os implantes estrangeiros, achando a "brasilidade modernista" (Moraes, 1988). Ao fazê-lo, há o intuito de inserir o país no "Concerto das nações" cultas, eruditas, mas sem o descarte do popular, tornando tênue a distinção entre erudição (aspecto exógeno) e popular (aspecto endógeno). Assim, o conceito de cultura não mais se sustentaria em uma essência, cujo elemento diferenciador seria a fronteira nacional, mas compondo um imbricamento entre local e global. Essa análise que propomos é representada no seguinte trecho do manifesto supracitado: “A síntese/ o equilíbrio/ o acabamento de carrosserie/ A invenção/ A surpresa/ Uma nova perspectiva/ Uma nova Escala" (Andrade, 2011).

Pôr o pé ou dar um pé na geografia? Eis um dos dilemas de Oswald de Andrade. A preocupação telúrica, expressa na busca por uma terra imaginada, nova e nacional, é uma tônica importante em sua arte, representando a necessidade do poeta de achar o lugar dele, seguro, onde firmar os pés e chamar de seu. Assim, a terra assume um caráter ambivalente, ora positivada em seu discurso, nessa busca por uma terra nova, ora negativada, pelo próprio reconhecimento do "homem vitimizado [pela opressão da] terra" como tema por excelência do que é o moderno, o qual Oswald identifica como nascente pelas mãos de Monteiro Lobato. Também há essa mesma ambivalência na eleição do "sentido de interior" como o lugar rurbano e das máximas potencialidades brasileiras ${ }_{1}^{10}$ pois, ao mesmo tempo em que a terra se coloca em relação ao seu povo, quando este é vítima dos símbolos da fábrica e da invisibilidade/impessoalidade típica dos grandes centros urbanos (também expresso em Sentido do interior), também há a possibilidade de preservar os valores e a civilidade rural, juntamente com a chegada dos vetores modernizantes. Isso é melhor entendido quando Oswald contrapõe Bauru, que ainda preserva a "civilidade rural", e a "cultura cínica das cidades", ao despojar a civilidade rural, tendo a capital paulista como exemplo maior dessa corrupção.

Ontem na PRG 8, a rádio de Bauru, essa estação que ainda não está deformada pelos

trejeitos e pela publicidade dos grandes centros, ouvimos a história da formação 
desta cesta de frutos ótimos da terra paulista. Sem a energia cívica de um edil e sem o desbravamento que precedeu a estrada de ferro, não teríamos esta metrópole do próximo hinterland, que avançando em iniciativa progressista e em apuramento técnico, não perdeu a base do seu trabalho agrícola e se orgulha de sua civilidade rural. Aqui, campo e cidade, agricultura, pecuária e mecânica, saúde e progresso dão-se as mãos, que são as mãos de todas as raças da terra. [...] Só assim o sentido do interior prevalecerá sobre o cosmopolitismo e a cultura corrupta e cínica das cidades. (Andrade, 1992: 192-193)

10 Além disso, a terra também é afirmada na antropofagia, homem que come e se alimenta da terra, tema desencadeado pelo assombro despertado pelo Abaporu de Tarsila do Amaral: o homem fincado à terra. O contexto do qual tratamos é, assim, dos escritos mais provocadores da década de 1920, o Oswald dos manifestos, figura de presença incendiária na fase mais radical e combativa do modernismo. Emergem daí a devoração (ressignificação) e o movimento (estilo telegráfico) como símbolos caros a Oswald que repercutiram fortemente na intelectualidade brasileira (modernista) como um todo, compondo dois aspectos decisivos na literatura oswaldiana, segundo Benedito Nunes (2011). O exímio intérprete e crítico Antônio Cândido (1977) explica o aspecto fragmentário que será marca da literatura oswaldiana, desde os primeiros romances, perpassando pelos manifestos e até seus ensaios que retomam a antropofagia e, por isso, relevantes de serem evidenciados:

'Fora sempre um fragmentário' - diz do protagonista d'A estrela de absinto. 'Em torsos quebrados, estudos largados, concentrava, numa predileção alegre e constante, a força reveladora de sua arte'. Nessas linhas (que exprimem muito do que sentia a seu próprio respeito) percebemos todo o drama de sua criação, posta entre ancestralidades poderosas e impulsos de liberdade, que nunca se harmonizem de modo a permitir uma inspiração unânime. Dissociaram-no, pelo contrário, em experiências sucessivas, semeando a sua obra de contrastes e mesmo contradições. (Candido, 1977: 55)

11 Como proposto por Antônio Cândido, Oswald pode ser comparado às suas personagens, de modo que, muitas vezes, a linha que separa criador e criatura é demasiado tênue, fazendo do escritor modernista um "problema literário". Embora Antônio Cândido (1977) refira-se especificamente a duas produções romanescas de Oswald, Memórias sentimentais de João Miramar e Serafim Ponte Grande, tentaremos defender que tal definição sugerida pelo crítico pode ser estendida às demais produções - notadamente as aqui analisadas. Apesar de, no que tange ao gênero literário, os ensaios e manifestos oswaldianos não poderem ser caracterizados como ficções, o caráter utópico qualifica sua produção como detentora desta natureza, de modo que Lucia Helena (1985), ao buscar uma síntese da vida e obra do autor, defenda que nele prevalece o ficcionista. Associaremos isso, como já dito, ao significado e ao lugar da utopia em suas formulações. Talvez Lucia Helena (1985) tenha captado em seu estudo o predomínio do Oswald ficcionista por conta de sua poética fragmentária, a qual compõe, como Oswald queria, um "romance-mural", ${ }^{11}$ expondo toda a complexidade do real. É outro o crítico que atenta para mais esse elo que compõe a literatura oswaldiana, em toda sua potência:

[uma] obra ambiciosa, que, valendo-se de processo simultaneísta, cinematográfico, se estilhaça em miríades de fragmentos - que são suas cenas breves, densamente povoadas de personagens de vária condição - como se fossem milhares de cacos de mosaico bizantino a compor amplo painel de toda uma dada circunstância histórica numa dada geografia. Vasto tempo e vasto espaço se condensam nessas páginas tantas vezes desordenadas, até caóticas, porém desordenadas e caóticas como a 
própria realidade de que foram arrancadas ou que tentam captar. (Brito, 1972:

107-108)

12 Assim, apesar da busca de uma unidade, Oswald é atravessado por debates entre seus pares, os intelectuais modernistas e as vanguardas europeias, apresentando fases distintas e complexas, de difícil ordenamento e capaz de ludibriar o crítico. É isso que Antônio Cândido (1977) reconhece em sua digressão sentimental sobre Oswald de Andrade, obra na qual faz uma reavaliação do amigo. O exímio crítico reconhece seu erro e aproxima-se empaticamente de Oswald, relacionando a sua juventude com aquilo que Oswald chamava de "chato-boy", ${ }^{12}$ termo por ele criado para se referir aos jovens acadêmicos da crítica literária das décadas de 1940 e 1950 da USP (tradição a qual encontra-se (ândido), os quais Oswald julgava não compreender a potência de sua obra. Com o mea culpa de Cândido, aprendemos que o monolitismo de Oswald não resiste a um olhar mais próximo e cuidadoso, frente aos perigosos embustes e armadilhas.

Oswald forjará um novo sentido nas temporalidades, através de uma ambivalência no interior do próprio modernismo ${ }^{13}$ para interpretar as bases espaciais da formação brasileira (aquilo que estrutura seu modo de interpretar o Brasil, não mais pela estrutura do latifúndio e da escravidão), imaginativa e geograficamente, ao lançar luz sobre as antípodas floresta (saber autóctone do "primitivo tecnizado") e da escola (a qual cabe a técnica). Ao que parece ser um procedimento dialético, proporá um enlace primitivista (valorização da matriz indígena, sob o signo do canibalismo, e não do índio romantizado e do matriarcado) sob a aguerrida do polêmico (escandalizando a cena modernista com a imagem do canibal, da devoração e da luta) (Nunes, 2011: 12). Ao assim o fazer, gerou afastamento, questionamento e crítica à tradição artísticobacharelesca sediada fora da terra brasileira, na medida em que, por outro lado, aciona as esperanças no futuro, nas utopias, apresentando a técnica como redentora e a serviço do ócio.

O estilo telegráfico proposto por Oswald de Andrade é uma materialização na forma escrita do seu movimento flâneur pelo espaço, traduzindo a interpretação do Brasil a partir de viagens para fora e dos contrastes estabelecidos nesse cotejamento de áreas, algo similar ao que fazem os geógrafos ao compararem regiões, diferenciando as áreas, duas a duas. Assim, como sugere Benedito Nunes, a poética oswaldiana estrutura-se no par mobilidade-devoração.

15 Por vezes, a devoração é consigo próprio, já que Oswald tem contradições talhadas não só na sua poesia, mas em si mesmo e em sua própria visão sobre si, sendo a um só tempo o arauto entusiasta do novo e o "conservador", vindo de uma oligarquia cafeeira, que se pretende porta-voz privilegiado do lugar do índio e do matriarcado, mesmo sendo homem e branco. É necessário que uma parte de Oswald, sua fidalguia, seja submetida à totemização, visto que está jogada na condição de tabu:

Quando digo a você que foi o povo quem desceu em São Vicente, é porque meus antepassados também desceram lá, há quatrocentos anos. E eu sou o povo. Do lado materno venho de uma decadência faustosa de guerreiros, os "fidalgos de Mazagão", a quem D. José I mandou dar de presente um pedaço do Amazonas. Esses senhores meus avós, segundo me informou Gilberto Freyre, eram de uma indolência desoladora para a colonização. O contrário dos açorianos, donde veio meu ramo paterno. É natural, pois, que, dentro de mim se debatam o trabalhador e o aristocrata, o homem da rua que atravessa na frente dos automóveis para não parar e o enlevado que quer ficar em casa escrevendo ou lendo. (Andrade apud Brito, 1972: 11) 


\title{
Oswald de Andrade e os grandes manifestos: um encontro de referências, um produto e uma busca da "realidade" (geográfica) brasileira
}

\author{
A POESIA "PAU BRASIL" é o ovo de Colombo - \\ esse ovo, como dizia um inventor meu amigo, em \\ que ninguém acreditava e acabou enriquecendo o \\ genovês. Oswald de Andrade, numa viagem a \\ Paris, do alto de um atelier da Place Clichy - \\ umbigo do mundo - descobriu, deslumbrado, a \\ sua própria terra. A volta à pátria confirmou, no \\ encantamento das descobertas manuelinas, a \\ revelação surpreendente de que o Brasil existia. \\ Esse fato, de que alguns já desconfiavam, abriu \\ seus olhos à visão radiosa de um mundo novo, \\ inexplorado e misterioso. Estava criada a poesia \\ "Pau Brasil". (Prado apud Andrade, 2003: 89)
}

A atitude burlesca e afirmadora da vida de Oswald provém, dentre outros, da influência nietzschiana, sob o símbolo da criança, acrescida da psicanálise freudiana. A interpretação dada por Antônio Cândido (1970) sugere um encantamento e uma descoberta do mundo através das viagens, ao tempo em que o espaço no Brasil era acompanhado de um olhar da falta, da incompletude. O próprio Oswald se imbui de traços infantis, expressos não só na burla e na criatividade, mas também naqueles vigentes em sua autobiografia pela observância às "ordens de mamãe": aquilo que denomina de sentimento órfico, ${ }^{14}$ que nunca se fez ausente, mesmo quando de maior filiação ao marxismo.

Em Oswald viajante, Cândido (1970) apresenta e interpreta a produção de Oswald de Andrade como sendo animada por sua primeira viagem à Europa, que representou um primeiro afastamento de sua terra e de seus familiares. Citando Baudelaire, compara Oswald a uma criança e a um flâneur, um incansável e curioso viajante a descobrir o mundo e, do umbigo deste - na Paris da Belle Époque - descobriu o Brasil, como o diria Paulo Prado:

Para sua personalidade, sabemos que foi decisiva a experiência da Europa, antes e depois da guerra de 1914. Na sua obra, talvez as partes mais vivas e resistentes sejam as que se ordenam conforme a fascinação do movimento e a experiência dos lugares. [...] entre o Novo e o Velho Mundo, exprimindo a posição do homem americano, que ele viveu com intensidade, ao adquirir consciência da revisão de valores tradicionais em face das novas experiências de arte e de vida. [...] Viajar para ele é não apenas buscar coisas novas, mas purgar as lacunas da sua terra [...] a viagem era também um meio de conhecer e sentir o Brasil, sempre presente, transfigurado pela distância. (Candido, 1970: 53-54)

Sentir a paisagem brasileira em seu frescor, a terra profunda de valores reprimidos pela conquista europeia, eis o que Oswald de Andrade busca em suas viagens pelo Brasil e, sobretudo, fora dele. Nesse sentido, o contato com as vanguardas europeias, o pensamento de Nietzsche, Freud e o tema do primitivismo e da antropofagia foram referências caras à produção intelectual de Oswald, que requalifica o debate a partir da visão autóctone: o que para eles era externo e exótico tratava-se de nossa própria base de formação, dirá Oswald. Desse modo, notadamente, Montaigne, Thomas Morus - 
assim como uma série de pensadores aludidos em citações rápidas e estonteantes fazem parte de um conjunto de referências, bem como o tão propalado marxismo para a fase de maior engajamento, filiado à causa socialista e ao Partido Comunista Brasileiro (PCB), além da crítica da filosofia antiga (messiânica), em ensaio que relaciona tais filosofias aos feitos do patriarcado.

19 Em A Arcádia e a Inconfidência, ensaio de 1945, Oswald fornece uma importante pista de roteiros que adotou em seu labor literário: se, por um lado, a poesia deve estar nos fatos, como brada em seu manifesto; por outro, a estética e a métrica poética devem andar pari passu às transformações políticas:

Os poetas da Escola Mineira não rompem com os cânones da Arcádia, ocupados que estão em libertar o Brasil. A roda da velha estética continua a girar. O seu sentido de revolução tem um primado, o político. O problema expressional não os atinge a ponto de fazê-los legislar. Estamos longe da Batalha do Ernani e da Semana de Arte de 22. (Andrade, 2011: 77)

20 A literatura que Oswald combate é herança de tal quadro, os parnasianos e a alta pompa, o lado douto e as dores anônimas de um Brasil que se queria descoberto, a partir da criação dos símbolos nacionais e de uma identidade, as quais vêm, dentre outros, com a fundação do Instituto Histórico e Geográfico Brasileiro (IHGB), no âmbito político, e do Romantismo, em sua estética literária. Aí se encontra o índio de José de Alencar, alvo de combate de Oswald, que requalifica o nativo via signo da antropofagia, da devoração.

21 Conforme nos lembra Vera Lúcia Figueiredo (1995), Oswald tem em mira o ato fundacional, o descobrimento do Brasil, o qual representou uma negação da cultura e das territorialidades dos grupamentos nativos. Longe de ser inocente e meramente econômica, a lógica da conquista colonial é simbólica, de modo que a sobreposição do poder político lusitano sobre a América vem através da afirmação cultural, o eurocentrismo, que "nega, elipsa a existência das sociedades indígenas que tinham a posse da terra e recalca o sentido guerreiro, ${ }^{15}$ violento, da ação dos conquistadores. Realiza, portanto, ironicamente, um primeiro encobrimento" (Figueiredo, 1995: 85).

É contra esse conjunto de referências, as quais estabelecem um Brasil onde "só há os nomes geográficos ou botânicos e as incompreensões do tupi" (Figueiredo, 1998: 108), que o literato modernista imposta sua crítica. Conforme salienta Figueiredo, tais interpretações do Brasil - tradicionais - permanecem (como o próprio Oswald constatara ao avaliar os inconfidentes) com a ótica e a exata medida do europeu, sua escala de mundo. Mero "território-texto aberto a nova conquista e/ou leitura" (Figueiredo, idem.). Tal ideia de território-texto é fundamental para a imagem do Oswald-infante-geógrafo do rurbano que propomos.

Como o conceito de texto-território nos permite avistar, não foi somente uma questão literária em si que estava em jogo, mas antes um aspecto político decisivo, de modo a sugerir uma nova configuração da literatura que não a aparte da produção e da vida social: a negação de um pedestal. Assim, Oswald capta uma referência através da qual não há lugar para a autonomia da arte frente à produção coletiva, tanto social quanto artística. $O$ papel do intelectual é o da transformação, lema que orientará sua produção em seu período de militância pelo PCB, entre 1931 e 1945. A Conjuração Mineira ganha especial relevo por significar o germe da emancipação política, suas primeiras manifestações e, assim, para nosso literato, "Foram Tomás Antônio Gonzaga, Cláudio 
Manuel da Costa e os dois Alvarenga, a constelação inicial de nossa independência literária e política" (Andrade, 2011: 111).

Todavia, tal não bastará ao espírito irrequieto de Oswald, que participará e incendiará como nenhum outro o modernismo e, a partir de tal marco, projetará uma redescoberta do Brasil e uma revisão do ato fundacional (o descobrimento ou, antes, o encobrimento), de modo a recuperar o índio guerreiro. Além disso, apresentará o diagnóstico da dependência e da cópia dos valores europeus, questionando o estatuto da dependência literária, política e econômica, sendo, assim, o centenário da emancipação um momento oportuno para refutar uma dependência substancial. Éramos ainda dependentes, "Preguiçosos no mapa-múndi do Brasil", ${ }^{16}$ desterrados de nossa própria terra, pois os valores que faziam dela uma terrae incognitae advinham de fora, do mapa mundi, urgindo, portanto, uma nova escala e um retorno, um acerto de contas com o elo perdido: o substrato do fundo subsolo de nossa raiz indígena. Por isso, a utopia oswaldiana se revestirá de contornos geográficos tensionados entre elementos opostos, como a "floresta" e a "escola", na busca pela constituição das bases territoriais. Bases duplas, como sugere no manifesto da poesia pau Brasil.

Uma vez referenciado e localizado em suas coordenadas, podemos nos dedicar às questões suscitadas pelos manifestos. O tema do primitivismo é olhado a partir do prisma nativo, e não do exótico, o que nos distinguiria da experiência europeia. Assim, a referência geográfica é um importante demarcador da imaginação. Mesmo em sua fase mais crítica, Oswald reconhece esse primitivismo nativo como o único (grande) achado da geração modernista de 20 (Nunes, 2011).

Segundo Nunes (op. cit.), o tema do primitivismo coloca no centro do debate, e no foco dos grandes problemas, fatores como o imaginário, o emocional e o pensamento mitopoético, de modo que a técnica "futurista" - da velocidade, do ritmo da cidade e do carro que anuncia sua pressa com a klaxon ${ }^{17}$ - não prescinde de um acerto de contas com o passado, estando o modernismo nessa tênue corda bamba, em que ora descamba para o primitivo, ora para o futuro, mas tendo o Brasil como lugar seguro e, ao mesmo tempo, fonte dos problemas e esperanças do futuro (utopia). Assim, a selva (floresta) do primitivo e a cidade de São Paulo (arquétipo e lugar da técnica e da reflexão sobre o moderno) irão requerer um novo conhecimento, e a escola, lócus de aprendizagem sobre um novo lugar, será produto dessa combinação singular de tempos, em que a selva e a escola produzem o Brasil rurbano:

Oswald de Andrade, condicionado por esse sobressalto, que já marca o Manifesto da Poesia Pau Brasil, tanto penderia para o primitivismo de natureza psicológica quanto para o da experiência externa na estética do cubismo, que Apollinaire estendeu, sem esquecer de associá-las à exaltação futurista da vida moderna nos grandes meios urbanos [...] O Manifesto [...] situa-se na convergência desses dois focos. [...] [É] um programa de reeducação da sensibilidade e da cultura brasileira. [...] Nos meios técnicos de produção, informação e comunicação da sociedade industrial [...] tem esse modo de conceber as condições objetivas, históricosociológicas, que o possibilitam, e que formam, em conjunto, uma nova escala de experiência perceptiva. (Nunes, 2011: 13-15. Grifos do autor)

27 Já em seu primeiro manifesto, Oswald de Andrade sugere um caminho que ruma ao rurbano, tendo ele apresentado como base dupla formadora de nossa nacionalidade (e espacialidade) as antípodas floresta e escola. Também na poesia liberta da clausura da forma e da gramatiquice, grande sorte de "erros" e "experimentações", há um projeto moderno da nacionalidade - tanto na poética (forma-conteúdo) quanto nas ficções e 
utopias. Porém, a consagração da técnica não poderia exercer pleno triunfo sobre nossa geografia diferenciada, rurbana, sob o preço de caracterizar uma civilidade artificial, que cultua as citações e imitações, a mímese, o lado douto. Assim coloca Oswald, com argúcia, seu ponto no manifesto pau-brasil:

o lado doutor, o lado citações, o lado autores conhecidos. Rui Barbosa, uma cartola na Senegâmbia. Tudo revertendo em riqueza. A riqueza dos bailes e das frases feitas. Negras de jóquei. Odaliscas no Catumbi. Falar difícil. o lado doutor. Fatalidade do primeiro branco aportado e dominando politicamente as selvas selvagens. O bacharel. Não podemos deixar de ser doutos. Doutores. País de dores anônimas, de doutores anônimos. O império foi assim. Eruditamos tudo. Esquecemos o gavião de penacho. A nunca exportação da poesia. A poesia ainda oculta nos cipós maliciosos da sabedoria. Nas lianas das saudades universitárias. (Andrade, 2011: 59-60).

E avalia, sobre isso, o crítico:

[A] prática que os engenheiros e os especialistas mobilizam, originou-se na nova escala de experiência condicionada pela máquina e pela tecnologia, por todo esse conjunto dos meios de produção, comunicação e informação da época moderna, que transformaram a natureza circundante, criando a sobrenatureza do meio técnico da civilização industrial e urbana, a escala não livresca mas espetacular de um mundo supreendentemente mágico, de coisas mutáveis, de objetos que se deslocam no espaço e no tempo - de um mundo em que a própria ciência funciona como varinha de condão. ${ }^{18}$

Para o crítico, o manifesto de 1924 é exatamente essa tentativa de conciliação da base dupla, a floresta e a escola, que estamos entendendo como símbolos de uma imaginação geográfica, duas antípodas, que se sintetizam no rurbano. Ele sugere ainda uma relação de universalidade com a regionalidade, de modo a não eleger nenhuma área como centro de difusão das experiências e dos valores. Assim, essa "geografia" brasileira tem lugar numa geografia universal que sempre a negou, a encobriu e desconsiderou seus nativos e seu habitat, levando Oswald a proclamar a emergência do homem novo no mundo novo. Explica o comentador que "[a] universalidade da época deixaria de ser excêntrica para ser concêntrica; o mundo se regionalizara e o regional continha o universal" (Nunes, op. cit.:19), retomando a colocação oswaldiana da necessidade de "ser regional e puro em sua época", em observância ao manifesto pau-brasil.

Com o Manifesto Antropófago, de 1928, há a implosão do constructo tradicional e, com ela, a negação da geografia enumerativa, enciclopédica e romanceada em suas regiões excessivamente naturalizadas. Oswald desloca o pêndulo para o urbano, para o futuro e para o conhecimento de base dupla anunciada no primeiro manifesto, mas um urbano que não é aquele conhecido pelo europeu. É um urbano muito rurbano, ainda desconhecido, uma terrae incognitae utópica, de poderosa força imaginativa e telúrica:

Foi porque nunca tivemos gramáticas, nem coleções de velhos vegetais. E nunca soubemos o que era urbano, suburbano, fronteiriço e continental. Preguiçosos no mapa-múndi do Brasil. [...] Filiação. O contato com o Brasil Caraíba. Oú Villegaignon print terre. Montaigne. O homem natural. Rousseau. Da Revolução Francesa ao Romantismo, à Revolução Bolchevista, à Revolução Surrealista e ao bárbaro tecnizado de Keyserling. Caminhamos. (Andrade, 2011: 47-48)

31 Oswald, já em seu primeiro manifesto, começa a tatear uma formação "plástica", anfíbia, que é uma imagem presente tanto na visão utópica de Oswald quanto no tema "rurbano" de Gilberto Freyre. ${ }^{19}$ No caso do literato modernista, a base dupla floresta e escola é um primeiro momento dessa imaginação geográfica. 
32 A geografia está presente mesmo na fase marxista, comumente diminuída pela crítica, por conta de seu viés supostamente "ideológico" e doutrinário. Todavia, devemos lembrar que essa filiação ideológica de Oswald de Andrade, ainda que crítica ao pensamento marxista, por meio do que define como uma "vacina antropofágica".

Voltando ao manifesto antropófago, Oswald irá se refugiar em uma espécie de ode ao misticismo, ao irracionalismo que vocifera contra o calendário - e nisso, junto, a temporalidade - do colonizador e as marcas deixadas. Essa fuga visa atentar para o desconhecimento sobre o nacional, sendo necessário dar um passo atrás, na direção do primitivo, para que, a partir dele, conheçamos um novo mundo. Uma terrae incognitae: "O mundo não datado. Não rubricado", que visa investir e destituir "Contra as elites vegetais. Em comunicação com o solo." ${ }^{0}$

Por outro lado, o urbano e o meio técnico em dinâmica e experiência crescente serviam de base material para divulgação e também de inspiração técnica, sem por isso escapar à crítica. Sem a coabitação com o elemento bárbaro, munido da técnica, a cidade seria demasiado artificial, lugar de empréstimos e mimeses: um urbano muito exógeno e muito aquém do que deveria preservar de sua antípoda - a selva. Esse descuido e esquecimento deliberado para com a outra base antípoda, a selva, por parte do saber que se claustra na cidade (escola) levará Oswald a se colocar "Contra as escleroses urbanas".

Antecipando a "geografia do riso" de seu último ensaio, o autor elege a alegria como a "prova dos nove". 0 "matriarcado da Pindorama" se apresenta como a terra imaginada de promessas futuras, onde o bárbaro tecnizado alegre encontra seu lugar de direito, em um novo calendário, o ano "374 da deglutição do bispo Sardinha", na "Piratininga".

o manifesto antropófago remete a uma posição política de destaque, segundo o comentador de Oswald de Andrade, Mário da Silva Brito (1972). Não somente uma nova arte e uma nova estética, mas uma nova arte-estética que esteja figurando como elemento politicamente favorável, e não a (des)serviço do "novo homem" na "nova terra", ou seja, os brasileiros ameríndios, o bárbaro tecnizado do Matriarcado da Pindorama. Oswald de Andrade retomará e afirmará esse lugar político de modo mais explicitado na Arcádia e a Inconfidência.

37 Duas correntes principais, assim, se digladiam no (e pelo) modernismo, um conservador e outro "radical". "O verdamarelismo, escamoteado de uma costela de Oswald, caracteriza-se por seu conservadorismo, por sua prudência, e funciona como uma diluição ou amaciamento dos propósitos violentamente revolucionários" (Brito, 1972: 75. Grifo do autor) de Oswald, enquanto que no Grupo Anta, autenticamente oswaldiano, afirma-se outro tom político, outro índio e afirmação de outra terra, a rigor, outro Brasil. Enquanto um cultua valores que posteriormente se aproximariam do Estado Novo varguista para dele se nutrir e alcançar um impulso político, o outro o rechaça.

O manifesto de 1928 ratifica a posição tomada no primeiro, promovendo nova ode ao primitivismo. Ainda não havia sido colocado por Oswald, cabalmente, a ideia da rurbanização freyriana, todavia, estava claro demais que a cidade europeia não era a nossa cidade anfíbia, rurbana, a qual Oswald apontará e encontrará em Bauru, quando em sua conferência, no ano de 1948. A civilidade artificial em novas terras brasileiras resultaria em tristeza, enquanto a "alegria é a prova dos nove". Assim, alegria e civilidade são contrapontos. 
Anterior ainda é a apropriação tomada pelo nativo e para o nativo, é a feita em que há uma celebração da alteridade: "Só me interessa o que não é meu. Lei do [novo] homem. Lei do antropófago.” (Andrade, 2011: 47). O crítico explana que:

A Antropofagia valoriza o homem natural, é antiliberal, anticristã, e foi inspirada no capítulo "De Canibalis" dos Ensaios de Montaigne. Nele se relata o episódio do índio brasileiro que observa à corte de Ruão muito se admirar do conforto da cidade europeia, mas se admirar muito mais de que não fossem os palácios e os salões queimados pelos habitantes dos cortiços e casebres, populações que viviam na lama e no frio, na fome e na miséria. Nele se conta também que "levado à presença do rei, que era uma criança doente, sentado no trono ao lado de um suíço barbado e terrível, o índio perguntara por que não tiravam dali aquele incapaz e não sentavam no trono suíço. (Brito, 1972: 75-76)

\section{Uma palavra contrária, a desgeografização}

$$
\begin{aligned}
& \text { uma tradição interpretativa de negar o lugar que reivindicamos para a geografia. Por } \\
& \text { quê? }
\end{aligned}
$$
oswaldiana, em particular, na produção dos manifestos, verificamos na crítica literária

41 Foi este desconforto e as inquietações dele decorrentes que motivaram a investigação desse problema. Assim, pretendemos localizar a produção literária e intelectual de Oswald de Andrade a partir de um diálogo com as reflexões modernistas e seus aspectos geográficos, entendendo a "geografia" de modo amplo, isto é, o Pensamento Geográfico, em particular, as imaginações. Sobre tal elasticidade e as possibilidades da geografia, o entendimento de Moraes (2008) é mais que oportuno, pois possibilita a integração e o imbricamento entre geografia, história e literatura. muito amplo e, a despeito disso, o lugar da geografia imaginativa contemplado pela crítica e teoria literárias é, se não "inexistente", insuficiente. Para contornar tal hiato, nós centramos as análises sobre o "espaço" oswaldiano empreendidas por destacados intérpretes que sugerem e chegam a adentrar problemas de interesse espacial, embora algumas interpretações venham a refutar a geograficidade de Oswald e não tratem o que fazem com a alcunha explícita de "geografia imaginativa". Dos poucos críticos que se aventuraram nos caminhos telúricos oswaldianos, quantidade ainda menor deles o viu de modo positivo.

A interpretação de Lucia Helena ${ }^{21}$ é, nesse sentido, sintomática, pois se configura como importante referência no campo e nos permite sustentar que parte bastante expressiva da crítica literária debruçada sobre a relação entre Oswald de Andrade e espaço geográfico afasta diametralmente o literato da geografia.

Ela defende a hipótese de que o literato modernista oscila entre uma postura alegórica (representação fragmentária) e simbólica (universal concreto que exprime uma visão de totalidade), sendo essas categorias entendidas à luz da filosofia de Walter Benjamin, decantada a partir do prisma da aura da obra de arte (em 0 drama barroco alemão). Segundo a intérprete de Oswald, seus momentos mais profícuos e criativos, de grande riqueza artística, estão atrelados à postura alegórica fragmentária, na qual estaria presente uma espécie de Oswald de Andrade artista. Já nos momentos universalizantes, de orientação simbólica, estaria presente o Oswald intelectual e panfletário, dos projetos salvacionistas e com tons de autoridade na condução da nacionalidade

Terra Brasilis, 11 | 2019 
brasileira em sua perspectiva moderna, sobretudo nas décadas de 30 e 40, uma vez sob filiação ao PCB.

Essa divisão operada por Lúcia Helena parece, em certos momentos, revestida de juízos de valores e enquadramentos maniqueístas, apesar do unânime reconhecimento da qualidade do trabalho, da autoridade e do conhecimento que apresenta com relação à crítica literária, sendo uma intérprete consagrada nesse cenário temático e no campo desses estudos.

Outro ponto que merece nossa crítica no interior do trabalho de Lucia Helena é o lugar que ela (não) dá à geografia. É sintomático o uso de metáforas geográficas - que além de aparecerem periodicamente em toda a tese, muitas vezes, indo além das metáforas, iniciam e concluem seu estudo, com passagens de ímpar alusão espacial.

$\mathrm{Na}$ análise da autora, a antropofagia oswaldiana é um "tecido alegórico de fragmentos" na qual há uma evocação da "heterogeneidade 'macunaímica' do nacional (Helena, op. cit:: 177). Assim, a intérprete identifica um encontro entre o maior projeto oswaldiano com a narrativa de Mário de Andrade sobre a brasilidade, defendendo que, em ambos, há essa progressiva "desgeografização" do Brasil. Todavia, Macunaíma trata da formação territorial e de uma viagem narrativa do espaço brasileiro, sendo antes uma nova geografia do Brasil. A despeito de o próprio Mário de Andrade montar um quadro que ele chama de "desgeografização", permanece inabalada e não problematizada que tipo de Geografia era essa, notadamente inspirada pelos conceitos ontológicos. Sobretudo o conceito de "região" que é colocado no centro de gravidade, na medida em que há uma coincidência entre a institucionalização da disciplina, arraigada no métier do geógrafo. É essa mesma região que será, através do somatório de cada uma dessas partes, a composição do quadro nacional, em conformidade aos auspícios da política varguista. Esta é a principal referência da Geografia brasileira que se institucionaliza na década de 1930, contemporânea aos Andrades, tendo por objeto a região personificada por sua singular paisagem. Ao mirar o todo, com Macunaíma, há uma explícita orientação em desmontar a geografia, pois a região se desfacelava.

A superação desses "geografismos" é, de certo modo, também necessária. Nesse sentido, a "desgeografização" da Geografia, aproxima esta disciplina às ciências humanas e das artes. A imaginação e a poética também encontram lugar em outra geografia que se fazia pelas mãos de Oswald, assim como a relação comunitária, animando sua produção intelectual. Em uma comparação com a Europa, a própria intérprete que evita o espaço permite uma leitura "telúrica":

se na Europa o que se afirmou foi a racionalidade como matriz prioritária do pensamento, no Brasil ainda é forte uma pulsão telúrica (não falamos aqui em "irracionalismo") em que o pensamento mágico, a relação comunitária, os vínculos com a tradição mostram-se prevalentes e determinam um hibridismo cultural peculiar. (Helena, 1985: 163)

Ao concluir a tese, a intérprete oscila novamente, parecendo redimir-se com a perspectiva pautada por Wolfgang Iser, ${ }^{22}$ tratando a literatura oswaldiana no contato com a "realidade" social, mas sem cair em determinismos que enquadrem fixamente a criatividade literária. A sombra da autonomia da arte parece distanciar-se. Refletindo sobre os últimos ensaios de Oswald de Andrade - marcados pela retomada da antropofagia dos manifestos dos anos 20 (A crise da filosofia messiânica e A marcha das utopias), Lúcia Helena mostra que Oswald ficcionista constrói um mundo só seu, que 
necessita habitá-lo, a despeito de seu isolamento no mundo (como a própria intérprete avalia), pois,

ao final, é o ficcionista que nele predomina, pensando o social e o político com as articulações que trabalha no nível literário. Os dois ensaios misturam, de um modo às vezes caótico, outras vezes inteligentíssimo, heranças vitais e montagens esdrúxulas. Nos dois ensaios Oswald se apresenta como um mesclador de caminhos que, se por vezes não nos levam, em termos teórico-científicos, a lugar preciso e rigoroso, têm a marca de um pensamento que jamais se conformou com o estabelecido, toda vez que isto coincidisse com a manutenção das distorções sociais, ou com o prejuízo coletivo em nome do individual. Nos compromissos que firmou, às vezes de modo desastrado e derrubando ao derredor, houve sempre o toque generoso de não caber em si, na festa da liberdade. - Mestre Oswald, este incansável "fazedor" de utopias. (Helena, 1985: 199. Grifos nossos.)

\section{BIBLIOGRAFIA}

Andrade, Oswald de (2002). Um homem sem profissão - sob as ordens de mamãe. São Paulo: Globo (Obras completas de Oswald de Andrade).

Andrade, Oswald de (2003). Pau Brasil. 2. ed. São Paulo: Globo (Obras completas de Oswald de Andrade). 232p.

Andrade, Oswald de (2011). A utopia antropofágica. São Paulo: Globo (Obras completas de Oswald de Andrade).

Brito, Mário da Silva (1972). As metamorfoses de Oswald de Andrade. São Paulo, Conselho Estadual de Cultura (Coleção Ensaio). 138p.

Chauí, Marilena (2000). Brasil: mito fundador e sociedade autoritária. São Paulo: Editora Fundação Perseu Abramo.

Creagh, Ronald (2010). "Reclus, ou a grande narrativa da terra”. In: Reclus, Élisée. Do sentimento da natureza nas sociedades modernas. Organização e tradução Plínio Augusto Coelho. São Paulo: Expressão \& Arte: Editora Imaginário, pp. 9-25.

Cruz, Valter do Carmo (2017). "Geografia e pensamento descolonial: notas sobre um diálogo necessário para a renovação do pensamento crítico”. In: Cruz, Valter; Oliveira, Denílson Araujo de (Orgs.). Geografia e giro descolonial: experiências, ideias e horizontes de renovação do pensamento crítico. Rio de Janeiro: Letra Capital, pp. 15-36.

Dardel, Éric (2011). o Homem e a Terra: natureza da realidade geográfica. São Paulo: Perspectiva.

Duqueviz, Beatris Camila (2006). A rurbanização como política social. 2006. Dissertação (Mestrado em Ciências Sociais em desenvolvimento, agricultura e sociedade) - Departamento de Ciências Sociais Aplicadas, Universidade Federal Rural do Rio de Janeiro, Seropédica.

Figueiredo, Vera Lúcia (1995). “Oswald de Andrade e a descoberta do Brasil”. In: Telles, Gilberto Mendonça. Oswald Plural. Rio de Janeiro: EdUERJ, pp. 85-92.

Gregory, Derek (1994). Geographical Imaginations. Cambridge (Massachusetts - USA); Oxford (UK): Blackweel Publishers. 
Helena, Lúcia (1985). Totens e tabus da modernidade brasileira: símbolo e alegoria na obra de Oswald de Andrade. Rio de Janeiro: Tempo Brasileiro; Niterói: Universidade Federal Fluminense. 213p.

Lacoste, Yves (2009 [1985/1988]). A geografia - isso serve, em primeiro lugar, para fazer a guerra. 15 ed. Campinas: Papirus. 264 p.

Maldonado-Torres, Nelson (2010). A topologia do ser e a geopolítica do conhecimento. Modernidade, império e colonialidade. In: Santos, Boaventura; Meneses, Maria Paula (Orgs.). Epistemologias do Sul. São Paulo: Cortez, pp. 337-382.

Moraes, Antônio Carlos Robert (2008). Território e História no Brasil. 3. ed. São Paulo: Anablume. $160 \mathrm{p}$.

Moraes, Eduardo Jardim de (1988). "Modernismo revisado". Revista Estudos Históricos (CPDOC/ FGV), Rio de Janeiro, v. 1, n. 2, pp. 220-238.

Nunes, Benedito (2011). “Antropofagia ao alcance de todos". In: Andrade, Oswald de. A utopia Antropofágica. São Paulo: Globo, 4. ed (Obras completas de Oswald de Andrade), pp. 7-56.

Prado, Paulo (2003). "Poesia pau brasil”. In: Andrade, Oswald de. Pau Brasil. 2. ed. São Paulo: Globo (Obras completas de Oswald de Andrade), pp. 89-94.

Pelletier, Philippe (2010). A Cidade e a Geogafia Urbana em Elisée Reclus e sua época. In: Coelho, P. A. (org.) Elisée Reclus. Renovação de uma cidade; Repartição dos homens. São Paulo: Expressão e Arte; Imaginário, p. 9-28.

Reclus, Elisée (2010). Renovação de uma cidade e Repartição dos homens. Organização e tradução Plínio Augusto Coelho. São Paulo: Expressão \& Arte: Editora Imaginário.

Tuan, Yi-Fu (1980). Topofilia: um estudo da percepção, atitudes e valores do meio ambiente. São Paulo: DIFEL.

\section{NOTAS}

1. No original, lê-se: “At one level, these imaginative geographies are uneven 'local knowledges' with their distinctive silences, blank spaces, and distortions [in another level...] our imaginative geographies (inside and outside academy) are global as well local. They articulate not simply the differences between this place and that, inscribing different images of here and there, but they also shape the ways in wich, from our particular perspectives, we conceive of the connections and separations between them. The "global" is not the "universal", in other words, but is itself a situated construction."

2. Na geografia, em particular a francesa, rurbano remete ao conceito de rurbanização. $O$ termo é apresentado por Pelletier (2010) em trabalho que realiza para estudar o lugar do fenômeno urbano na produção reclusiana. O autor observa uma tensão na geografia da época: "Esse mundo ainda é essencialmente rural ou selvagem. Daí o interesse voltado seja ao campo, símbolo de um povoamento milenar [...], seja aos espaços virgens, potencialmente povoáveis. Élisée Reclus não escapa dessa tendência dominante. [...] tem, pessoalmente, mais interesse pelos espaços rurais, 'rurbanos"' [...] (Reclus, 2010b: 9. Grifo nosso.). Numa perspectiva mais familiar e que de fato dialoga diretamente com Oswald e explicitamente referenciada por ele é a concepção de rurbanização de Gilberto Freyre. Nela, segundo Duqueviz (2006), está apontada a perspectiva da totalidade da ideia de brasilidade como oriunda à administração unitária e centralizada do Estado por parte dos lusitanos para com a colônia. Tal tradição coloca em xeque as proposições regionalistas, então associadas ao caudilhismo e aos interesses particularistas das instâncias locais e dos poderes descentralizados que comprometeriam as instituições. Em suma, para o 
pernambucano, a questão regional está associada à rurbanização, ratificando sua expressão geográfica.

3. Todavia, no afã de organizar o desenvolvimento e os desdobramentos dessa imaginação geográfica oswaldiana, valer-nos-emos de um corpus mais variado dos escritos do literato, perpassando por outros gêneros textuais, para além do formato de manifesto e aforismos.

4. Com a expressão "espírito infante" pretendemos designar a influência do filósofo Nietzsche na postura do escritor. O pensador alemão tem na figura da criança uma atitude radical de afirmação da vida, ao passo de não querer parar de brincar. 0 termo infante aqui refere-se tanto a esse traço do infantil quanto a uma atitude "belicosa", de infantaria, que Oswald assume contra a velha estética e o mofo dos valores exógenos (sintetizados no estilo parnasiano).

5. Há um relativo e substancial consenso de que, por conta de seu radicalismo, a simples presença de Oswald de Andrade, ou o aparecimento de seu nome, já gerava estrépito entre os setores mais conservadores. As vaias sofridas durante a Semana de 22 são muito marcantes nesse sentido. Após seu desencanto com a brasilidade modernista a serviço do nacionalismo (uma cultura nacional), ele se autointitula "palhaço da burguesia", ao revisionar a obra do período, quando negou sua ideia tida como de maior envergadura: a antropofagia. $O$ escritor sempre se prostrou contra a figura de Getúlio Vargas, associadas à ditadura (inclusive ele produz o primeiro volume de sua série de romance, Marco Zero, intitulada de A revolução melancólica, em alusão à crise constitucionalista de 1932). Seu jornal, em parceria com Pagu, chegou a ser empastelado pelos estudantes de direito do Largo de São Francisco (SP). Ao final da vida, seus esforços consistem em atribuir uma unidade de seus projetos, resgatando a tese da antropofagia, agora submetida a um marxismo também crítico, em contexto de desilusão e nova ruptura, agora com relação ao PCB.

6. Por "geografia nova" entendemos que há uma crítica à geograficidade, notadamente à "Geografia Sentimental" de Plínio Salgado. Embora o escritor não esboce um intuito explícito de forjar uma geografia nova, há indícios de uma crítica aos "geografismos" (o apego ao trato da região enquanto essência que compõe a nação e seu corpo, o território), cujas formas naturais como os rios e as cores da natureza se mostram como formas vazias de significados e conteúdo. Oswald de Andrade chega a afirmar que o Brasil é "uma geografia parada à espera da história" (Livro da convalescença de Oswald de Andrade apud Fonseca, 2007). Partilhamos e partimos do entendimento sobre a geograficidade deriva da leitura de Yves Lacoste (2009). Para este geógrafo, a construção de uma geografia "enfadonha" e não explicativa que se vulgariza nas escolas e, no caso brasileiro, a enumeração de objetos vazios como a quantificação dos topônimos de relevo, de apelo à memória dos afluentes de rios, em que o recurso da "sentimentalidade" tenta travestir coisas em si, vazias de significado, artificialmente ao corpo da nacionalidade. É essa "geografia seca”, cuja crítica vem no relato dos portos de segunda ordem, como se queixará Oswald. Também é digno de destaque o neologismo geograficidade introduzido de modo seminal por Yves Lacoste (idem) e, a partir dele, comportando vasta abertura polissêmica. O termo ilumina o problema da marcação - quase sempre arbitrária - do que é ou não "geográfico"; em suma, o estatuto científico dos objetos geográficos. Ele propõe um paralelo análogo ao termo historicidade e, ao analisar a comparação entre as duas ciências, defende que como resultado houve o progressivo alargamento dos horizontes da história frente ao fechamento epistemológico da ciência geográfica. Lacoste defende ainda uma atitude colada à geograficidade na qual propõe a "articulação dos conhecimentos relativos ao espaço, que é a geografia, e um saber estratégico, um poder." (p. 28). Já para Vesentini, apresentador da $15^{\circ}$ edição da tradução brasileira da obra, o termo está associado a questões ontológicas: "a geograficidade [...] para ele [Lacoste] se define essencialmente com referência à cartografia e, de forma especial, à noção de escala".

7. A alusão é explicitada à luz do pensamento de Freud, o qual, juntamente com o de Nietzsche, configura grande referencial sobre o qual a produção oswaldiana do período (anos 20) gravita. 0 tabu constitui o recalque, a negação e a ambivalência decorrentes do parricídio e do incesto, 
sendo o alvo o chefe que organiza a vida da horda. Assim, os valores entronados - para Oswald, a tradição eurocêntrica, que nega o nacional e que tem como elementos os estigmas da dominação colonial, sua arquitetura e o negro - representam as referências hegemônicas. Isto é, tais valores que tradicionalmente eram negados (e, por isso, tabu) serão colocados de modo afirmativo e referencial para Oswald, convertendo tabu em totem. Em outras palavras, tratava-se exatamente de valorizar os tabus que remetem ao colonial, ao que é "nosso", ao que outros flancos da modernidade visavam suprimir. Isso é expresso, por exemplo, nas demolições da arquitetura colonial de que a capital da República foi alvo, cujo emblema maior foi a Reforma de Pereira Passos, nos anos iniciais do século passado.

8. Notadamente, a obra Urupês e a personagem de Jeca Tatu.

9. Conferência proferida na cidade de Bauru, em 1948, onde Oswald celebra a preservação de uma "civilidade rural" no "hinterland" do Brasil, e, por outro lado, aponta para a miserabilidade crescente frente ao processo de urbanização.

10. A imagem, geralmente ufanista (e evitada por Oswald), que pinta uma natureza generosa e reserva ao futuro o desenvolvimento do país. Sobre isso, vide a análise de Carlos Walter Porto Gonçalves sobre a Amazônia como representação de uma imagem do próprio Brasil (país do futuro). Gonçalves, Carlos Walter Porto (2005). Amazônia, Amazônias. São Paulo: Editora Contexto.

11. A noção de "romance-mural" é um termo que o autor autoatribui a sua séria de romances intitulada Marco Zero, que foi planejada em cinco volumes, dos quais somente dois foram finalizados e publicados: 1 - A revolução Melancólica e 2 - Chão. Frequentemente, tal produção é (des)qualificada como panfletária. Oswald se vale da inspiração das pinturas de murais mexicanas [Silva, Ana Maria Formoso Cardoso. (2003). Marco Zzero de Oswald de Andrade: uma proposta de romance rural. 2003. 178f. Dissertação (Mestrado em Teoria Literária) - Universidade Estadual de Campinas, Instituto de Estudos da Linguagem, Campinas]. Essa noção se associa à construção de um panorama da cena paulista e brasileira. Ela tem íntima relação com a escrita fragmentária que confere simultaneidade, denominada de telegráfica (ou cinematográfica). Vide-se sobre isso Brito (op. cit).

12. Segundo Ângela de Castro Gomes: "eram críticos que recusavam o improviso e o álcool, preferindo um outro padrão de trabalho e de bebida: muita reflexão e refrigerantes. Um verdadeiro escândalo e desgosto para vários contemporâneos integrantes de uma geração marcada pela boemia. Daí a designação inspirada de Oswald de Andrade, atribuindo ao grupo um certo espírito: 'os chato-boys'". In: Gomes, Angela de Castro. (1998). Sociologia dos chato-boys. Disponível em: <http://www1.folha.uol.com.br/fsp/resenha/rs14119807.htm>. Acesso em: 26/09/2016.

13. Aqui é importante sinalizar a distinção marcante entre o culto ao tempo futuro e ao primitivismo, e não ao passadismo, mas a história encoberta, silenciada e dos subsolos.

14. Remete ao sentimento de religiosidade que Oswald defende como pertencente à natureza humana. O autor a coloca como "vontade de crer", sustentando o âmbito do irracional (e do primitivismo). Acreditamos que embora, num primeiro olhar, pareça contraditório, essa formulação intelectual - que é uma certeza para Oswald - não é somente fruto da orfandade da mãe quando volta às pressas da viagem à Europa, em 1912, sem, contudo, conseguir chegar antes do padecimento dela. A influência do pensamento de Freud, do Nietzsche e as leituras enviesadas para resolver suas próprias questões contribuem a ideia do sentimento órfico. Do mesmo modo, a opção de Oswald, notável orador, a fazer troça e ironia, foi confundido como pouco sério e comprometido com sua empresa. Assim, o sentimento órfico reflete a perda, de início da mãe, mas também valha para um "rapto" e indiferença a sua obra, cujo reconhecimento não chegou a ter de volta em vida.

15. Vide a ideia romântica do bom selvagem.

16. Aforismo do Manifesto Antropófago (1928). 
17. Quando o automóvel ainda era um símbolo incipiente da modernidade, na qual pairava um espírito de completo espanto com o novo, o termo "buzina" ainda não era corrente para designar o alerta sonoro que atenção de sua passagem. A buzina era conhecida pelo nome de sua marca, klaxon. Assim, ao nomear uma revista com o substantivo próprio da marca, a intenção era acenar ao moderno, ao novo e as transformações por vir, chamando atenção para si, assim como o faz a buzina do carro.

18. Nunes, Ibid: 17.

19. Vide Duqueviz (2006).

20. Aforismo do Manifesto Antropófago (1928). Vide Andrade, 2011: 49-50.

21. Ibid.

22. Uma das principais referências da Teoria da Recepção, que desloca a construção dos significados de uma suposta intenção imperativa do autor com a sua obra, como se tivesse total controle e consciência sobre ela (uma das acepções do historicismo) para a recepção da obra, em seu trânsito entre os pares intelectuais e intérpretes, inclusivo extemporâneos. Essa perspectiva condiz mais com o entendimento da articulação entre arte e sociedade, e não da autonomia da primeira frente à segunda.

\section{RESUMOS}

O artigo discute a imaginação geográfica na literatura de Oswald de Andrade a partir da análise da produção mais (re)conhecida, expressiva e característica do escritor modernista. Destacamos a interpretação que o autor propõe sobre o Brasil nos manifestos da década de 1920 e sua significância geográfica, quer seja, sua geograficidade. Na conclusão, enveredamos ainda brevemente pelo problema da "desgeografização" no diálogo com a crítica literária, apontando algumas lacunas que esta parece ter deixado, após confrontá-la com a análise da imaginação geográfica procedida a partir dos manifestos oswaldianos.

El artículo discute la imaginación geográfica en la literatura de Oswald de Andrade a partir del análisis de la producción más (re)conocida, expresiva y característica del escritor modernista. Destacamos la interpretación que el autor procede sobre Brasil en los manifiestos de la década de 1920 y su significancia geográfica, sea, su geografía. En la conclusión, se trata de una cuestión de "desgeografización" en el diálogo con la crítica literaria, señalando algunas de las lagunas que ésta parece haber dejado, tras confrontarla con el análisis de la imaginación geográfica procedente a partir de los manifiestos oswaldianos.

The article discusses the geographical imagination in the literature of Oswald de Andrade from the analysis of the most recognized, expressive and characteristic production of the modernist writer. We emphasize the author's interpretation of Brazil in the manifests in the 1920s and its geographical significance, that is, its geography. In conclusion, we turn briefly to the problem of "degeographization" in the dialogue with literary criticism, pointing out some gaps that this seems to have left, after confronting it with the analysis of the geographical imagination derived from the Oswald's manifests.

L'article traite de l'imagination géographique dans la littérature d'Oswald de Andrade à partir de l'analyse de la production (re)connue, expressive et caractéristique de l'écrivain moderniste. Nous soulignons l'interprétation de l'auteur du Brésil dans les manifestes de la décennie de 1920 
et son importance géographique, c'est-à-dire sa géographie. En conclusion, nous abordons brièvement le problème de la "dégéographisation" dans le dialogue avec la critique littéraire, en soulignant quelques lacunes qu'il semble avoir laissées, après l'avoir confrontée à l'analyse de l'imagination géographique dérivée des manifestes oswaldiens.

\section{ÍNDICE}

Índice geográfico: Brasil

Índice cronológico: 1924-1928

Mots-clés: imaginaire géographique, la rurbanisation, Oswald de Andrade, le modernisme, littérature

Keywords: geographical imagination, rurbanization, Oswald de Andrade, modernism, literature Palavras-chave: imaginação geográfica, rurbanização, Oswald de Andrade, modernismo, literatura

Palabras claves: imaginación geográfica, rurbanización, Oswald de Andrade, modernismo, literatura

\section{AUTOR}

\section{FELIPE CAVALCANTI}

Doutorando em Geografia no PPGEO-UERJ

felipegeouff2008@gmail.com 